\title{
A escola vai ao museu: ações e percepções dos professores nesse percurso
}

Guilherme Cordeiro da Graça de Oliveira

cordeiro@iq.ufri.br

0000-0002-4924-7018

Universidade Federal do Rio de Janeiro, Rio de Janeiro, Rio de Janeiro, Brasil.

Palloma dos Santos de Araujo Guimarães

pallomaaraujo@yahoo.com.br 0000-0003-0125-4953

Universidade Federal do Rio de Janeiro

Patrícia Monteiro

patriciamonteiro579@gmail.com 0000-0002-1637-1514

Universidade Federal do Rio de Janeiro

\begin{abstract}
RESUMO
Entre os professores de Ensino Médio é quase unânime a constatação da desmotivação discente para os estudos das ciências naturais. A pesquisa em ensino de ciências investiga metodologias e procura desenvolver sequências didáticas alternativas capazes de reverter essa situação e despertar entre os jovens o interesse e a motivação para os estudos. Uma dessas práticas corresponde à utilização de espaços não formais de educação. Nesse artigo foram identificados e analisados o comportamento e as percepções de professores durante visitas escolares ao Espaço COPPE Miguel de Simoni, no Rio de Janeiro. Os instrumentos utilizados foram entrevistas semiestruturadas, observações não participantes e questionários. Os resultados obtidos revelaram que os professores, embora cientes da importância dessas atividades extraclasse, desconhecem as características próprias da aprendizagem nesses espaços. Diante dessa constatação algumas recomendações são enfatizadas para o docente envolvido com atividades escolares em museus ou em outros espaços não formais.
\end{abstract}

PALAVRAS-CHAVE: Educação em museus. Espaço COPPE Miguel de Simoni. Comportamento docente. 


\section{INTRODUÇÃO}

O desinteresse dos estudantes com relação às ciências naturais é assunto recorrente na maioria das rodas de conversas entre professores. Aparentemente, os alunos aprendem cada vez menos e têm menos interesse pelo que deveriam aprender. As dificuldades enfrentadas pelos alunos, possivelmente responsáveis pelo referido desinteresse, são de naturezas diversas, passando por lacunas conceituais, ausência de estratégias de raciocínio e solução de problemas de cunho científico e desvinculação da realidade vivenciada pelo discente (POZO; CRESPO, 2009).

Fourez (2003) aponta que o ensino de ciências deve permitir que os alunos compreendam sua importância dentro de um contexto histórico. Na mesma linha de argumentação, Chassot (2003) admite que não se pode mais conceber propostas para um ensino de ciências sem incluir nos currículos componentes que estejam orientados para os aspectos sociais e pessoais dos estudantes.

Visitas escolares a Espaços Não Formais de Educação (ENFE), tais como museus e centros de divulgação científica, constituem uma temática de investigação que aborda aspectos teóricos e práticos relacionados aos diferentes atores envolvidos. Estudos ligados aos modelos de aprendizagem no ambiente museal (FALK; STORKSDIECK, 2005; ESHACH, 2006; BAMBERGER; TAL, 2007), educação em museus (MARANDINO; IANELLI, 2012; COLOMBO; AROCA; SILVA, 2009), ensino de ciências (HAUAN; KOLSTO, 2014; PLAKITSI, 2013), interações museu-escola (KÖPTCKE, 2014; OLIVEIRA; MARCONSIN, 2014) e comportamento de professores e alunos (KISIEL, 2005; TAL; STEINER, 2006) são alguns exemplos onde essa temática é investigada com métodos e objetivos distintos.

Apesar dos diferentes objetivos, na literatura existe uma quase unanimidade de que essas visitas são capazes de proporcionar oportunidades de aprendizagem valiosas aos estudantes (KISIEL, 2005). De fato, museus e centros de divulgação científica podem "contribuir significativamente para a compreensão da ciência e estimular os estudantes a prosseguir em seus interesses além da escola" (NATIONAL RESEARCH COUNCIL, 1996, p. 45). No Brasil, as Orientações Curriculares para o Ensino Médio recomendam o desenvolvimento de práticas fora do espaço escolar, apontando esse procedimento como uma atividade potencialmente motivadora, já que desloca o ambiente de aprendizagem para fora de sala de aula (BRASIL, 2006).

Para um professor que pretenda elaborar uma agenda de visitas a ENFE, a realidade brasileira apresenta uma série de empecilhos de natureza prática ou de formação inicial que dificultam um efetivo trabalho com objetivos educacionais. A falta de apoio institucional e as dificuldades quanto ao aspecto logístico podem se tornar preocupantes e desestimulantes para o professor que se depara com as diversas tarefas e responsabilidades envolvidas tais como os agendamentos junto à escola e ao local a ser visitado; o transporte e o lanche para os alunos, a sua substituição por outro professor na escola; o termo de permissão do responsável; a responsabilidade sobre a segurança e o comportamento dos alunos. Vencidas todas essas etapas, o professor se depara também com as deficiências na sua formação inicial, onde a educação nos espaços não formais não foi sistematicamente abordada. Essas deficiências emergem quando o professor tem 
apropriar do acervo, planejar atividades antes, durante e após a visita e a avaliar todo o processo. Com todas essas preocupações adicionais, o que acontece com frequência é que o aspecto pedagógico fica negligenciado e, quando se consegue organizar uma agenda de visitas, essas assumem o perfil de um passeio sem qualquer preocupação com os conteúdos, o que caracteriza uma subutilização de um espaço rico em potencialidades educativas para os jovens.

Nesse trabalho investigam-se as percepções e o comportamento de professores durante visitas guiadas a um Centro de Ciências do Instituto Alberto Luiz Coimbra de Pós-graduação e Pesquisa em Engenharia (COPPE) denominado Espaço COPPE Miguel de Simoni - Tecnologia e Desenvolvimento Humano. Os dados da pesquisa foram obtidos através de entrevistas semiestruturadas, observações não participantes e questionários. O comportamento dos professores foi avaliado como participativo, tradicional ou passivo, segundo critérios adotados por Tal e Steiner (2006).

\section{PERCEPÇÃO E COMPORTAMENTO DOS PROFESSORES DURANTE VISITAS A ENFE}

Do ponto de vista dos professores é consenso que visitas a museus ou outros ENFE constituem uma prática potencialmente enriquecedora que pode auxiliar principalmente na motivação para o estudo dos conteúdos curriculares. Falk, Dierking e Foultz (2007) relatam uma investigação na qual foi solicitado aos professores que apontassem as características que melhor descrevessem o ideal de uma visita guiada. Dois eixos com as características preferenciais foram propostos para avaliação sendo o primeiro Informação (foco nos conteúdos) versus Inspiração (foco na criatividade) e o segundo sendo Ação (reflexão e participação) versus Passividade (aprendizagem mecânica). A maioria dos professores revelou preferir a combinação Informação/Ação e um segundo grupo escolheu a combinação Informação/Passividade. Esta visão por parte dos professores evidenciou a preferência por aspectos relacionados à aprendizagem escolar tradicional onde o foco se situa nos conteúdos e do aluno espera-se uma atitude passiva de recepção. $\mathrm{O}$ fato dos aspectos relacionados à criatividade $\mathrm{e}$ participação terem sido menos citados revela ainda o desconhecimento por parte de alguns professores dessas características como diferenciais da educação no espaço museal.

Robins e Woolland (2003) entrevistaram professores após a realização de visitas de grupos escolares ao Victoria and Albert Museum de Londres. Inicialmente os autores identificaram, entre os professores e educadores do museu, diferentes pontos de vista com relação ao que seria uma visita bem sucedida. Para os educadores do museu, uma visita bem sucedida seria aquela na qual os estudantes identificassem alguma relevância no nível pessoal e se sentissem confortáveis, enquanto que, para os professores o sucesso da visita estaria relacionado diretamente ao trabalho prático desenvolvido. Os autores identificaram também algumas percepções, traduzidas a seguir, que revelaram dificuldades para os professores:

P1 - Ter que pensar rapidamente em seus próprios pés porque pode haver uma peça no caminho ou um trabalho sobre o qual você não leu ou não reparou... isto é bastante diferente da situação em sala de aula quando você está no controle e é o centro do espetáculo; P2 - Pode ser muito estranho falar para 
um grupo de alunos num ambiente de uma galeria, as pessoas pensam que você está falando de forma muito vaidosa; P3 - Eu acho que o papel muda completamente, você é um facilitador, um treinador ao invés de um professor.

Esses discursos revelam as apreensões dos professores quanto a conduzir uma visita num museu. P1 revela o receio por não conhecer bem os objetos do acervo; P2 ressalta o constrangimento ao ter que falar em público na presença de outras pessoas além de seus alunos e P3 ressalta as especificidades da educação museal, na qual o professor transmissor tradicional do conhecimento é substituído pelo professor mediador/facilitador. Desta forma, fica evidente que é necessário um grande entendimento e estratégias de colaboração entre professores e educadores de museus a fim de favorecer a aprendizagem dos estudantes.

Hauan e Kolsto (2014) realizaram uma ampla análise documental sobre exposições em ambientes de comunicação científica enquanto ambientes de aprendizagem. A eficácia de diferentes recursos, atividades e ambientes educacionais foi investigada principalmente com relação a aprendizagem de conceitos científicos. Foram discutidos aspectos relacionados a elaboração das visitas (liberdade de escolha versus orientação), a temática das exposições, tarefas e questionários propostos, utilização de narrativas, utilização da tecnologia e mediação. Para os autores, os resultados encontrados na literatura devem ser interpretados tendo em vista que liberdade de escolha e orientação são características que facilitam a motivação e mantém o foco durante as visitas.

O aparente conflito entre liberdade de escolha e orientação necessita de um ponto de equilíbrio. Para Bamberger e Tal (2007), esse ponto de equilíbrio está num modelo de visita descrito como escolha limitada, onde os estudantes são orientados a executar tarefas de acordo com um tema previamente discutido com o professor ou apresentado pelo museu.

Um efetivo trabalho educativo que envolva visitas escolares a museus ou centros de divulgação científica é aprimorado na medida em que professores e profissionais museais trabalhem em consonância. Reconhecendo as especificidades do trabalho educativo em cada ambiente (escola e museu), é importante que professores e profissionais museais trabalhem no sentido de aproximar os acervos dos conteúdos curriculares. Os professores podem organizar atividades pré e pós visitas que tenham por objetivo buscar a melhor apropriação do acervo para trabalhar os conteúdos do currículo escolar, instigar a curiosidade dos estudantes e reforçar e avaliar a aprendizagem.

Bossler e Nascimento (2013) investigaram a participação de professores em situação de visitas escolares a espaços museais. Através da análise dos discursos produzidos pelos 15 professores entrevistados (indicados pelo pessoal do museu por serem professores que agendam suas visitas regularmente), os objetivos do trabalho foram: (i) identificar e analisar os papéis atribuídos a professores e agentes culturais (mediadores); (ii) analisar museu e escola enquanto ambientes de aprendizagem caracterizando suas possibilidades educativas; (iii) caracterizar atividades desenvolvidas na escola antes e depois das visitas; (iv) conhecer a utilização que os professores fazem dos recursos oferecidos pelos museus e (v) identificar elementos na fala dos professores que justifiquem as saídas com seus alunos em suas práticas. Na visão dos professores entrevistados, o professor não concorre com o agente cultural (mediador) quanto ao conhecimento acerca do 
museu. $\mathrm{O}$ agente cultural é um profundo conhecedor do museu e transita com segurança conforme um roteiro específico. A competência e o treinamento do agente cultural conferem ao museu maior potencial educativo. Embora as atividades desenvolvidas por professores e agentes culturais se aproximem em muitos aspectos, para os entrevistados, funções outras além de ensinar são atribuídas aos agentes culturais. $O$ aspecto lúdico e a capacidade de divertir foram citados como funções que distinguem as atividades de professores em sala de aula e agentes culturais nos museus.

Além disso, a situação particular gerada durante a visita pode potencializar a aprendizagem dos alunos. As características específicas da aprendizagem museal facilitam que o aluno atribua significados aos conceitos trabalhados em sala de aula; aproprie-se de bens culturais; tenha acesso à dimensão concreta do conhecimento e sinta-se estimulado ao questionamento. A principal atividade pré-visita citada pelos professores foi uma conversa com os alunos com o intuito de chamar à atenção para aspectos tais como as possíveis conexões entre o acervo e os conteúdos curriculares, esclarecer as regras de conduta no museu, reforçar a curiosidade dos alunos e estimular que os alunos recuperem histórias pessoais que possam ser usada como exemplos. Entre os professores entrevistados, somente 7 declararam que realizavam alguma atividade pós vista. Os demais alegaram como motivos da não realização dessas atividades, o excesso de atividades docentes e o cronograma. A atividade pós visita mais citada foi também uma conversa com a finalidade de averiguar aprendizagens, congregar informações reunidas ao longo da visita e sugerir possíveis conexões (BOSSLER; NASCIMENTO, 2013).

Kisiel (2005) investigou a motivação dos professores envolvidos em visitas a ENFE em Los Angeles (EUA). Numa fase inicial da pesquisa 400 professores foram escolhidos ao acaso, contatados por correio eletrônico e convidados a responder um questionário com questões abertas e fechadas investigando, entre outros aspectos, as motivações, estratégias, avaliação, objetivos e realização de atividades pré e pós-visitas. As respostas obtidas - 115 professores retornaram o questionário - permitiram a codificação de 8 motivações. Embora essas motivações não tenham sido ranqueadas em termos de importância, em frequência de citações a possibilidade de conexão com o currículo escolar foi apontada por 90 \% dos professores. Em alguns casos essa motivação foi citada como pré-requisito para a visita. Segundo o protocolo adotado, a motivação se relacionava a essa categoria para "qualquer menção da relação da aprendizagem no museu com o trabalho em sala de aula" (p. 954). Além disso, nessa categoria de motivação estavam descritas várias respostas que relacionavam a visita ao currículo escolar - tais como reforço, relação, enriquecimento, suporte, complementação etc. As demais motivações codificadas, suas descrições e frequências estão descritas na Tabela 1.

Ainda com relação ao trabalho de Kisiel (2005), foi perguntado também aos professores quais seriam os indicadores de uma visita bem-sucedida. Para o autor, as respostas a essa questão dependeriam ao menos em parte das motivações iniciais e objetivos. A análise dos resultados revelou 7 indicadores de sucesso das visitas: (i) Experiência positiva (os estudantes se divertem, conversam sobre a visita, não querem voltar para a escola etc); (ii) Demonstração de novos conhecimentos (aprendizagem de algo novo determinado por uma discussão após a visita); (iii) Conexão com o currículo escolar (os estudantes 
reconhecem pontos em comum entre as discussões durante a visita e o currículo escolar); (iv) Desenvolvimento das motivações e interesses (os estudantes demonstram ter gostado da experiência e se interessaram em aprender mais); (v) Bom comportamento (engajamento dos estudantes durante as visitas); (vi) Quantidade e natureza das questões (capacidade de formulação de questões) e (vii) Visita sem incidente (ninguém se perde ou se machuca). A partir desses indicadores, o autor identificou inconsistências e lacunas nas respostas dos professores. Por exemplo, embora $90 \%$ dos professores tenham citado como uma motivação a conexão com o currículo escolar, somente $23 \%$ reconheceram que uma visita bem sucedida seria aquela onde os estudantes reconhecessem as relações dos temas tratados na visita com os conteúdos curriculares.

Tabela 1 - Identificação das motivações, descrição e frequência de citação dos professores (KISIEL, 2005, p. 941).

\begin{tabular}{|c|c|c|}
\hline Motivação & Descrição & $\begin{array}{c}\text { Porcentagem } \\
\text { de citação }\end{array}$ \\
\hline $\begin{array}{l}\text { Conexão com o } \\
\text { currículo escolar }\end{array}$ & $\begin{array}{l}\text { Consideram as visitas como oportunidades } \\
\text { de reforço e expansão do currículo escolar }\end{array}$ & 90 \\
\hline $\begin{array}{l}\text { Proporcionar novas } \\
\text { experiências }\end{array}$ & $\begin{array}{l}\text { Consideram as visitas como uma } \\
\text { oportunidade única para os estudantes. }\end{array}$ & 39 \\
\hline $\begin{array}{l}\text { Proporcionar uma } \\
\text { experiência de } \\
\text { aprendizagem }\end{array}$ & $\begin{array}{c}\text { Consideram que as vistas proporcionam } \\
\text { aprendizagens em geral. }\end{array}$ & 30 \\
\hline $\begin{array}{l}\text { Despertar interesse e } \\
\text { motivação }\end{array}$ & $\begin{array}{c}\text { Consideram as visitas como um evento } \\
\text { capaz de despertar interesse e motivação } \\
\text { nos estudantes }\end{array}$ & 18 \\
\hline $\begin{array}{l}\text { Mudança do local e } \\
\text { da rotina }\end{array}$ & $\begin{array}{l}\text { Oportunidade de deixar a sala de aula e } \\
\text { promover uma mudança na rotina. }\end{array}$ & 17 \\
\hline $\begin{array}{l}\text { Promover uma } \\
\text { aprendizagem para a } \\
\text { vida }\end{array}$ & $\begin{array}{l}\text { As visitas proporcionam uma aprendizagem } \\
\text { para a vida além da escola. }\end{array}$ & 13 \\
\hline $\begin{array}{l}\text { Proporcionar } \\
\text { diversão e } \\
\text { recompensa }\end{array}$ & $\begin{array}{c}\text { Professores consideram que as visitas } \\
\text { podem ser uma experiência positiva e } \\
\text { divertida para os alunos }\end{array}$ & 11 \\
\hline $\begin{array}{c}\text { Atender às } \\
\text { demandas da escola }\end{array}$ & $\begin{array}{l}\text { Os professores participam das visitas para } \\
\text { atender à demanda da escola }\end{array}$ & 3 \\
\hline
\end{tabular}

Com relação aos potenciais conflitos entre professores, administradores dos locais visitados e a direção da escola, gerados quando as expectativas dos professores não são atendidas, Kisiel (2005) sugere medidas simples a serem tomadas. Por parte da escola é importante que as visitas sejam agendadas com a participação dos professores. Tendo em vista a importância das atividades pré e pós visita, as datas devem ser cuidadosamente escolhidas de forma a permitir ao professor a elaboração dessas atividades. Datas próximas de exames escolares e no final do ano letivo devem ser evitadas. Por parte dos administradores dos espaços a serem visitados seria enriquecedora a disponibilização de um 
profissional do museu para um momento de discussão com os alunos antes ou após a visita. Seria também importante o conhecimento dos conteúdos escolares para que os mesmos fossem enfatizados durante a visita.

Da mesma forma como proposto por Falk e Storksdieck (2005), as principais motivações que apresentam os professores numa visita relacionam ao entretenimento (diversão) e a aprendizagem. No entanto, as experiências de visitas escolares a ENFE se diferenciam quanto ao aspecto de livre escolha ressaltado por esses autores e comum ao público espontâneo.

Wolinski et al. (2011) investigaram professores e alunos visitantes no Parque da Ciência Newton Freire-Maia (Curitiba - PR) procurando identificar se o professor estabeleceu ou explicitou objetivos para a visita e de que forma os conhecimentos trabalhados durante a visita foram consolidados pelos alunos. Foram investigados 8 professores e 132 alunos através da aplicação de questionários depois das visitas. Embora todas as escolas possuíssem laboratório, 3 professores enfatizaram o aspecto prático e a possibilidade de interação como o principal objetivo da visita. Para esses respondentes, o fato da escola possuir laboratório não é suficiente para que os conhecimentos fossem vivenciados na prática. Dois objetivos relacionavam-se aos conteúdos escolares; 2 objetivos relacionavam-se a aprendizagem em geral, 1 objetivo relacionava-se com a possibilidade da visita despertar o interesse e o encantamento pela ciência; 1 objetivo enfatizou a possibilidade de demonstrar a aplicação da ciência e tecnologia e 1 objetivo relacionava-se a cultura e lazer. Para 6 professores investigados, a visita se relacionou com algum conteúdo escolar e 5 professores declararam que houve algum tipo de preparação prévia para a visita. Todos os professores concordaram que a visita era importante e atribuíram a importância da visita a: enriquecimento do conhecimento científico e cultural; fixação de conteúdos; fuga da rotina; possibilidade de relacionar teoria e prática e possibilidade de gerar motivação. Os professores reconheceram a importância das práticas em ambientes não formais para que os estudantes possam compreender a sociedade contemporânea em seus diversos aspectos. No entanto, nas palavras dos autores:

Por outro lado, preocupou-nos uma visível desconexão com o conteúdo abordado em sala de aula, como se os museus e centros servissem apenas como momentos de descontração da formalidade do conhecimento imposta pela escola (WOLINSKI et al. 2011, p. 147).

Com essas palavras os autores expressam a necessidade de se trabalhar com objetivos específicos quando se almejam resultados em termos de aprendizagem de conteúdos curriculares. Embora reconhecendo que a escola apoia atividades não formais, somente um professor relatou que na escola existe um projeto relacionado com essas atividades. Este resultado revelou a desconexão entre os objetivos da visita e a vinculação com a aprendizagem. Segundo Wolinski et al. (2011) o objetivo maior, não revelado, é o entretenimento. Os autores sugerem que a temática da educação em espaços não formais seja trabalhada na formação inicial e continuada dos professores para que essas atividades sejam aproveitadas não somente como um momento de lazer mas também com acompanhamento de aprendizagens específicas.

Oliveira et al. (2014) publicaram um trabalho onde a elaboração, aplicação e avaliação de visitas guiadas ao Museu Nacional, no Rio de Janeiro - RJ, foram 
descritas a partir do Modelo de Aprendizagem Contextual (FALK; STORKSDIECK, 2005). O público investigado foram alunos de 9o ano do ensino fundamental, 1으, $2^{\circ}$ e 3 ํanos do ensino médio. Os autores concluíram que a dinâmica empregada nas visitas foi capaz de conferir ganhos afetivos e cognitivos aos alunos visitantes e que, segundo o modelo, o contexto físico do Museu Nacional se adéqua principalmente aos alunos do ensino médio.

Para os profissionais dos museus, com relação às visitas guiadas como a principal forma de interação das equipes educativas com os públicos escolares, Pereira e Braga (2013) afirmam que:

\footnotetext{
...o grande desafio está posto aos museus para um diálogo profícuo com a escola no sentido de estimular experiências significativas para professores e estudantes, relacionando os tempos de pré-visita, visita e pós visita com articulações entre as demandas docentes e os projetos educativos dos museus (PEREIRA; BRAGA, 2013, p.90).
}

O comportamento dos professores que acompanharam as turmas visitantes a um centro de ciências em Israel foi investigado por Tal (2001) e Tal e Steiner (2006). Tal (2001) classificou, após um estudo piloto com 30 visitas, o comportamento do professor como participativo (PAR), disciplinador (DIS) ou passivo (PAS). O professor PAR foi identificado como aquele que planeja as visitas, está ativamente envolvido, faz perguntas, solicita explicações ao guia, sugere ideias, ajuda os alunos nas atividades e procura ligações com o currículo escolar. O professor DIS apresenta um comportamento tradicional, fazendo o seu melhor para manter os alunos na tarefa e fornece ajuda administrativa. Ele se preocupa principalmente com a disciplina. O professor PAS enfatiza o fato de que a visita não é sua responsabilidade. Esse professor está muitas vezes focado em atividades irrelevantes à visita ou sequer acompanha a turma.

Após o estudo piloto, Tal e Steiner (2006) investigaram o comportamento de 102 professores considerando as percepções dos profissionais museais, observações dos pesquisadores e a autopercepção dos professores. Segundo as observações obtidas, $21,5 \%$ dos professores apresentaram comportamento PAS, $57,0 \%$ o comportamento DIS e $21,5 \%$ o comportamento PAR.

\section{O ESPAÇO COPPE MIGUEL DE SIMONI - TECNOLOGIA E DESENVOLVIMENTO HUMANO}

O Espaço COPPE constitui um centro de difusão científica vinculado ao Instituto Alberto Luiz Coimbra de Pós-Graduação e Pesquisa em Engenharia, da Universidade Federal do Rio de Janeiro (UFRJ), situado no Centro de Tecnologia dessa instituição, no campus da Ilha do Fundão. Trata-se de uma atividade de extensão, dirigida principalmente a professores e alunos do último segmento do Ensino Fundamental e do Ensino Médio, da região metropolitana do Rio de Janeiro. Seu principal objetivo é utilizar experimentos e outras mídias educativas para auxiliar o ensino de ciências ministrado em instituições de Ensino Básico (BARTHOLO; CAMPOS, 2009). 


\section{METODOLOGIA}

Nesse trabalho foi utilizada uma metodologia que envolveu entrevistas semiestruturadas, aplicação de questionários em escala de Likert de 4 níveis e observações diretas não participantes. Foram avaliados 13 professores durante 13 visitas realizadas entre os meses de agosto e novembro de 2017.

A visita teve como foco a exposição permanente, seguindo o roteiro previamente preparado pela coordenação pedagógica do local (BARTHOLO; CAMPOS, 2009). O Espaço COPPE é separado por nichos temáticos, cada qual tratando de um dos seguintes assuntos: Organismos e Mecanismos; Sociedade e Meio Ambiente; Informação e Conhecimento; Trabalho, Serviços e Entretenimento; Matéria e Energia \& Mundo Virtual.

Inicialmente, alunos e professores visitantes foram recepcionados com uma apresentação sucinta sobre a COPPE e o próprio Espaço COPPE. Os visitantes foram então divididos em grupos e conduzidos aos nichos pelos monitores. A permanência em cada nicho foi de aproximadamente 20 minutos, durante os quais os estudantes tomaram contato com experimentos, ouviram apresentações e tiraram dúvidas sobre os temas ali tratados. A recepção, condução pelos nichos e mediação foram realizadas por monitores, alunos de graduação e pósgraduação da UFRJ, bolsistas de extensão, capacitados para o trabalho de mediação pela equipe de coordenação pedagógica e por pesquisadores da COPPE pertencentes aos laboratórios parceiros. Entende-se que a mediação realizada por esses monitores é um elemento fundamental para o aprendizado propiciado pela visita à exposição permanente. A visita encerrou com uma reunião dos grupos no mesmo ponto em que foi feita a recepção.

Na chegada do grupo escolar ao Espaço COPPE, após apresentação do pesquisador e do trabalho a ser desenvolvido, foi solicitado ao professor responsável permissão para as entrevistas e para acompanhar o grupo durante a visita. Seguia-se então a entrevista inicial a qual tinha por objetivo conhecer os perfis da escola (se pertencente à rede pública ou particular), dos alunos (a escolaridade e o gênero), do professor (disciplina que leciona e se era professor regente da turma visitante) e dos procedimentos prévios (se houve ou não alguma preparação prévia dos alunos para a visita).

As observações durante a visita focaram principalmente no comportamento do professor. No Espaço COPPE toda a visita é guiada por mediadores treinados e o professor responsável fica livre para acompanhar ou não o grupo. Para cada professor, identificado por P1 até P13, foram anotadas as características que pudessem evidenciar um comportamento participativo (PAR), disciplinador (DIS) ou passivo (PAS) conforme descrito por Tal e Steiner (2006). Com relação aos alunos foi observado o comportamento geral do grupo (se houveram perguntas diretas ao mediador, conversas paralelas relacionadas ou não com a mediação, interação com os objetos das exposições, utilização de telefones celulares etc).

Após a visita foi solicitado ao professor que respondesse a um questionário formado em parte por assertivas para concordância em escala de Likert de 4 níveis e por perguntas diretas. Esse questionário teve por objetivo obter informações sobre a percepção do professor a respeito do seu próprio comportamento durante a visita e sobre a intenção de realizar algum trabalho pós visita com os alunos. 


\section{RESULTADOS E DISCUSSÃO}

Dos 13 professores entrevistados, somente 6 eram efetivamente docentes regentes da turma de alunos visitantes. Para os demais não foi possível a elaboração de atividades pré e pós-visita. Nesse caso os professores foram escalados pela direção da escola para acompanhar a turma - qualquer outro profissional da escola poderia fazê-lo. Este procedimento negligencia as potencialidades em termos de aprendizagem oferecidas em ENFE.

Foram investigadas 8 visitas com alunos de ensino médio e 5 visitas com alunos do ensino fundamental com um total de 167 alunos - 84 meninos e 83 meninas. Somente 3 professores relataram que fizeram atividades pré-visita sendo que dois deles não descreveram a atividade e um professor relatou que procurou "estabelecer relações entre o acervo do espaço e a disciplina que leciona". Atividades pós-visita tais como trabalhos em grupo ou relatórios foram relatadas por 6 professores. As atividades pré-visita servem para que o aluno tome contato, mesmo que superficialmente, com o local a ser visitado e com as atividades propostas, minimizando o que se conhece na literatura como efeito surpresa o qual, se presente em demasia é capaz de gerar ansiedade e euforia prejudiciais à mediação e ao trabalho docente (ESHACH, 2006). Por outro lado, as atividades pós-visita constituem uma oportunidade de discussão, aprofundamento, análise e compartilhamento das experiências vivenciadas um reforço do aprendizado desenvolvido na visita. A importância de se realizarem atividades antes e após as visitas foi investigada na literatura por Eshach (2006) e Lourenço e Paiva (2010).

O questionário aplicado aos professores após as visitas foi elaborado com 5 itens em escala de Likert de 4 níveis. Nesse tipo de questionário o respondente deve atribuir um valor de 1 a 4 às assertivas onde 1 significa discordo, 2 significa discordo em parte, 3 significa concordo em parte e 4 significa concordo. Dessa forma, pode-se calcular a média $M$ das respostas para cada assertiva de acordo com a Equação 1.

$$
\mathrm{M}=\frac{1}{13} \sum_{i=1}^{i=13} n_{i}
$$

Onde $n_{i}$ corresponde à resposta do respondente i. Ao se calcular a média entre as respostas obtidas, quanto mais próxima ela estiver de 4, maior a concordância dos respondentes com aquela assertiva. Deve-se ressaltar, no entanto que, ao se calcular a média numa escala de dados ordinais tal como a escala de Likert, duas suposições devem ser consideradas. A primeira é que todos os entrevistados têm uma compreensão comum do significado de cada categoria de resposta e a segunda é que existe uma distância igual entre cada categoria da variável. A principio, dados ordinais não permitem sua 
manipulação aritmética, somente sua classificação, porém, segundo Rea e Parker (2000) essa manipulação tornou-se aceita porque se considera que o poder das informações obtidas supera de longe os custos associados ao relaxamento desses aspectos técnicos.

Desta forma, optou-se por apresentar os resultados obtidos no questionário através da media entre as respostas. A Tabela 2 apresenta as assertivas e as respectivas médias. Como pode ser observado, as assertivas 1,2 e 4 apresentaram medias superiores a 3,5 revelando que o conjunto de professores investigado procurou prestar atenção à mediação, esclarecer as próprias dúvidas e manter a disciplina dos alunos. Segundo Tal (2001), este resultado aponta no sentido de comportamentos classificados como PAR e DIS. A média obtida na assertiva 3 revelou que os professores concordaram em parte que procuraram esclarecer as dúvidas dos alunos, o que também está associado ao comportamento PAR. A média da assertiva 5 (de semântica negativa) revelou que os professores se preocuparam com a mediação revelando também um comportamento do tipo PAR.

Tabela 2 - Assertivas e médias obtidas pelo conjunto de professores investigados

\begin{tabular}{|c|c|}
\hline Assertiva & Média \\
\hline 1 - Prestei atenção à mediação & 3,84 \\
\hline $\begin{array}{c}2 \text { - Procurei esclarecer minhas } \\
\text { próprias dúvidas }\end{array}$ & 3,54 \\
\hline $\begin{array}{l}3 \text { - Procurei esclarecer as dúvidas } \\
\text { dos alunos }\end{array}$ & 3,15 \\
\hline 4 - Procurei manter a disciplina & 3,54 \\
\hline $\begin{array}{c}5 \text { - Não me preocupei com a } \\
\text { mediação }\end{array}$ & 1,46 \\
\hline
\end{tabular}

Foi também solicitado a cada professor que assinalasse uma entre três alternativas seguintes, aquela que mais se aproximava do que ele percebia como teria sido sua participação na visita: (i) Procurei principalmente acompanhar a mediação e esclarecer as minhas dúvidas e as dúvidas dos alunos; (ii) Procurei principalmente manter a ordem entre os alunos e (iii) A mediação não me preocupou pois não era minha responsabilidade. Cada alternativa resume um comportamento seja PAR (alternativa i), DIS (alternativa ii) ou PAS (alternativa iii). Os resultados obtidos foram comparados às observações feitas durante as visitas. A Tabela 3 apresenta os resultados obtidos quanto à disciplina lecionada, o comportamento observado e a percepção própria dos docentes investigados. 
Conforme pode ser verificado na Tabela 3 o comportamento PAS foi observado para 3 professores (P2, P9 e P12). No entanto, nenhum professor, segundo sua percepção própria, se atribuiu esse comportamento. 0 comportamento DIS foi observado para 3 professores (P3, P8 e P11) e assumido por 5 (P2, P3, P5, P9 e P10). O comportamento PAR foi observado para 7 professores (P1, P4, P5, P6, P7, P10 e P13) e assumido por 8 (P1, P4, P6, P7, P8, P11, P12 e P13). A concordância entre o comportamento observado e a percepção própria ocorreu para 6 professores (P1, P3, P4, P6 , P7 e P13) com 5 concordâncias para o comportamento PAR e 1 para o comportamento DIS.

Cabe ressaltar ainda que os 5 professores cujas observações dos pesquisadores e a percepção própria apontaram para o comportamento PAR são professores que efetivamente eram regentes da turma visitante. De fato, somente esses têm a possibilidade de desenvolver atividades pré e pós visitas, reconhecidas na literatura como essenciais para um efetivo trabalho educativo em museus (ESHACH, 2006). Para os demais professores, mesmo reconhecendo a importância da atividade, a atuação se limitou ao momento da visita e se caracterizou principalmente por comportamentos do tipo DIS ou PAS.

Tabela 3 - Disciplina lecionada, comportamento observado e percepção própria dos professores investigados.

\begin{tabular}{cccc} 
Professor & $\begin{array}{c}\text { Disciplina(s) que } \\
\text { Leciona }\end{array}$ & $\begin{array}{c}\text { Comportamento } \\
\text { Observado }\end{array}$ & $\begin{array}{c}\text { Percepção } \\
\text { Própria }\end{array}$ \\
\hline P1 & Biologia & PAR & PAR \\
P2 & Química & PAS & DIS \\
P3 & Português & DIS & DIS \\
P4 & Ciências & PAR & PAR \\
P5 & Ciências & PAR & DIS \\
P6 & Português & PAR & PAR \\
P7 & Matemática/Física & PAR & PAR \\
P8 & Ens. Fundamental & DIS & PAR \\
P9 & Matemática/Física & PAS & DIS \\
P10 & Biologia & PAR & DIS \\
P11 & Ens. Fundamental & DIS & PAR \\
P12 & Matemática & PAS & PAR \\
P13 & Matemática & PAR & PAR
\end{tabular}

\section{CONSIDERAÇÕES FINAIS}

Embora reconhecendo a importância dos ENFE como potencialmente promotores da aprendizagem, parte dos professores que participaram desta pesquisa, seja por não ser docente da turma visitante, seja por desconhecer as 
especificidades da aprendizagem no ambiente museal, atuou como um acompanhante para a turma e percebeu a visita unicamente como um momento de diversão para os alunos, sem qualquer compromisso entre os assuntos tratados na visita e o conteúdo curricular abordado na escola. Resultado semelhante foi obtido por Wolinski et al. (2011) os quais observaram que, embora não seja admitido, o objetivo maior da visita é o entretenimento.

Para que visitas guiadas de grupos escolares a museus de ciências ou a qualquer outro ENFE sejam aproveitadas como oportunidades de aprendizagem, é preciso que professores e educadores dos locais - conhecedores respectivamente do currículo escolar e do acervo em exposição - atuem em sinergia oferecendo atividades diferenciadas, lúdicas e desafiadoras que, para além da aprendizagem formal, desenvolva no estudante o gosto pela ciência e a motivação para continuar aprendendo fora da sala de aula.

Um programa que envolva visitas a ENFE deve considerar as atividades pré e pós-visita. De fato, um dos benefícios das atividades pré-visita é atenuar o efeito surpresa que gera grande ansiedade no grupo de visitantes (ESHACH, 2006). Por outro lado, para Lourenço e De Paiva (2010) atividades pós-visita podem atuar como um reforço do aprendizado exercendo um efeito de retroalimentação entre motivação e aprendizagem.

Assim, acredita-se que, para o professor, um efetivo trabalho que envolva visitas a ENFE deve começar e terminar na sala de aula. 


\title{
The school goes to the museum: actions and perceptions of teachers in this path
}

\begin{abstract}
Among the teachers of High School is almost unanimous the confirmation of student demotivation for the studies of the natural sciences. Research in science education investigates methodologies and seeks to develop alternative didactic sequences capable of reversing this situation and awakening interest and motivation among students. One of these practices corresponds to the use of non-formal educational settings. In this article, the behavior and perceptions of teachers during school visits to the Miguel de Simoni Center of Science in Rio de Janeiro were identified and analyzed. The instruments used were semi-structured interviews, non-participating observations and questionnaires. The results showed that teachers, although aware of the importance of these extraclass activities, are not aware of the characteristics of learning in these settings. Faced with this, some recommendations are emphasized for the teacher involved in school activities in museums or other non-formal settings.
\end{abstract}

KEYWORDS: Museum education. Miguel de Sinomi center of science. Teacher behavior. 


\section{REFERÊNCIAS}

BAMBERGER, Y.; TAL, T. Learning in a personal context: levels of choice in a free choice learning enviroment in science and natural history museum. Science Education, New Jersey, v. 91, n.1, p.75 - 95, 2007.

BARTHOLO, R.; CAMPOS, A. A Experiência do Espaço COPPE Miguel de Simoni Tecnologia e Desenvolvimento Humano, Revista Virtual de Gestão de Iniciativas Sociais, p. 47-52, 2009. Disponível em:

<www.Itds.ufrj.br/gis/espaco_miguel.htm> Acesso em: 01 dez. 2017.

BRASIL. Ministério da Educação, Orientações curriculares para o ensino médio. Ciências da natureza, matemática e suas tecnologias. Ministério da Educação Educação Básica, 2006.

CHASSOT, A. Alfabetização científica: uma possibilidade para inclusão social. Revista Brasileira de Educação, Rio de Janeiro, n. 22, p. 89-100, 2003.

COLOMBO, J.; AROCA, S.; SILVA, C. Educação Em Centros De Ciências: Visitas Escolares Ao Observatório Astronômico Do Cdcc/Usp, Investigações em Ensino de Ciências, Porto Alegre, v.14, n.1, p. 25-36, 2009.

ESHACH, H. Bridging in-Scholl and out-of-school learning: formal, non-formal and informal learning, Journal of Science Education and Technology, Gainesville, v. 16, n.2, p. 171-190, 2006.

FALK, J.; DIERKING, L.; FOULTZ, S. In Principle, in practice - Museum as Learning Institutions, Lanham: Altamira Press, 2007.

FALK, J.; STORKSDIECK, M. Learning science from museums, História, Ciência e Saúde, Rio de Janeiro, v. 12, p. 117-198, 2005.

FOUREZ, G. Crise no ensino de Ciências? Investigação em Ensino de Ciências, Porto Alegre, v. 8, n. 2, p. 109-123, 2003.

HAUAN, N.; KOLSTO, S. Exhibitions as learning environments: a review of empirical research on students' science learning at Natural History Museums, Science Museums and Science Centers, Nordic Studies in Science Education, Oslo, v.10 n.1, p. 90-104, 2014. 
KÖPTCKE, L. Museologia e Patrimônio - Revista Eletrônica do Programa de PósGraduação em Museologia e Patrimônio - Unirio | MAST, Rio de Janeiro, v. 7, n.2, p. 15-35, 2014.

LOURENÇO, A.; DE PAIVA, M. (2010). A motivação e o processo de aprendizagem. Ciências \& Cognição, Rio de Janeiro, v.15, n.2, p. 132-141, 2010. Disponível em: <http://www.cienciasecognicao.org/revista/index.php/cec/article/view/313>. Acesso em: 26 dez. 2016

MARANDINO, M.; IANELLI, I.T. Modelos de educação em ciências em museus: análise da visita orientada. Revista Ensaio, Belo Horizonte, v.14, p.17-33, 2012.

NATIONAL RESEARCH COUNCIL. National science education standards, Washington, DC, National Academy Press, 1996.

OLIVEIRA, G. et al. Visitas guiadas ao Museu Nacional: interações e impressões de estudantes da Educação Básica. Ciência \& Educação, Bauru, v. 20, n. 1, p. $227-$ $242,2014$.

OLIVEIRA, G.; MARCONSIN, N. O impacto de uma atividade não formal no cotidiano da escola, Ciências \& Cognição, Rio de Janeiro, v. 19, n.3, p. 477-492, 2014.

PEREIRA, J.; BRAGA, J. Museu e experiências docentes, Ensino em Re-Vista, n. 1, p. 83-93, 2013.

PLAKITSI, K. Teaching Science in Science Museums and Science Centers. In: Activity Theory in Formal and Informal Science Education. Sense Publishers, p. 27-56, 2013.

POZO, J.; CRESPO, M. A aprendizagem e o ensino de Ciências: do conhecimento cotidiano ao conhecimento científico. Porto Alegre: Artmed. p. 14-28, 2009.

REA, L.; PARKER, R. Metodologia de Pesquisa: do planejamento à execução, São Paulo: Pioneira, 2000.

ROBINS, C.; WOOLLAND, V. Creative Connections: working with teachers to use museums and galleries as a learning resource. London: 2003. Disponível em < http://eprints.ioe.ac.uk/3400/1/Robins2003Creative1.pdf>. Acesso em 12 fev, 2017. 
TAL, T. Incorporating field trips as science learning environment enrichment - an interpretive study, Learning Environments Research, Netherlands, v. 4, n. 1, p. 25-49, 2001.

TAL, T.; STEINER, L. Patterns of teacher-museum staff relationships: School visits to the educational centre of a science museum. Canadian Journal of Science, Mathematics and Technology Education, Ontario, v.6, n. 1, p. 25-46, 2006.

WOLINSKI, A.; AIRES, J.; GIOPPO, C.; GUIMARÃES, O. Por que foi mesmo que a gente foi lá? Uma investigação sobre os objetivos dos professores ao visitar o Parque da Ciência Newton Freire-Maia, Química Nova na Escola, v. 33, n.3, p. 142-152, 2011.

BOSSLER, A.; NASCIMENTO, S. Modus operandi do professor em situação de visita a espaços museais: práticas e ritos preparatórios, ao longo e após a realização da visita, Ensino Em Revista, v. 20, p. 95-110, 2013.

Recebido: 2018-04-10

Aprovado: 2018-07-04

DOI: $10.3895 /$ rbect.v12n2.8144

Como citar: OLIVEIRA, G. C. G.; ARAUJO, P. G. S.; MONTEIRO, P. A escola vai ao museu: ações e percepções dos professores nesse percurso. Revista Brasileira de Ensino de Ciência e Tecnologia, v. 12, n. 2, 2019. Disponível em:

<https://periodicos.utfpr.edu.br/rbect/article/view/8144>. Acesso em: xxx.

Correspondência: Guilherme Cordeiro da Graça de Oliveira - cordeiro@iq.ufrj.br Direito autoral: Este artigo está licenciado sob os termos da Licença Creative Commons-Atribuição 4.0 Internacional. 